\title{
Nas origens do romance brasileiro: As primeiras narrativas de J. M. Pereira da Silva*
}

\author{
In the origins of the Brazilian novel: the first narratives of J. M. Pereira da Silva
}

\author{
VANIA PINHEIRO CHAVES \\ Universidade de Lisboa: CLEPUL. Lisboa, Portugal.
}

Dr

\begin{abstract}
Resumo: Este ensaio se debruça sobre as seis narrativas que, publicadas por J. M. Pereira da Silva no periódico carioca Gabinete de Leitura, em 1837, não tiveram o seu pioneirismo reconhecido pelos historiadores e críticos da literatura brasileira. A análise dos temas, assuntos e formas desses relatos procura demonstrar o importante contributo do autor para a criação e nacionalização da prosa de ficção brasileira.

Palavras-chave: romantismo brasileiro; prosa de ficção; J. M. Pereira da Silva; Gabinete de Leitura .

Abstract: This essay focuses on the six narratives that, published by J. M. Pereira da Silva in the Rio newspaper Gabinete de Leitura, in 1837, didn't have its pioneering role recognized by the historians and critics of Brazilian Literature. The themes, subjects and forms analysis of these stories seeks to demonstrate the author's important contribution to the creation and nationalization of Brazilian prose fiction.
\end{abstract}

Keywords: Brazilian romanticism; prose fiction; J. M. Pereira da Silva; Gabinete de Leitura.

\section{Introdução}

Fundador da cadeira no 34 da Academia Brasileira de Letras, João Manuel Pereira da Silva ${ }^{1}$ nasceu em 1817, na vila de Iguaçu², na Província do Rio de Janeiro - e faleceu em $1898^{3}$. Filho do comerciante português Miguel Joaquim Pereira da Silva e de Joaquina Rosa de Jesus, o escritor fluminense formou-se em Direito, no final da década de 30 do século XIX ${ }^{4}$, em Paris, onde se relacionou com o grupo da revista Niterói. De regresso ao Brasil, exerceu a advocacia, colaborou na imprensa e fez carreira política no Partido Conservador, tendo sido eleito deputado e, posteriormente senador.

Ficcionista, poeta, crítico literário, tradutor, historiador e biógrafo, Pereira da Silva deixou um vasto conjunto de obras. Como historiador, escreveu, entre outras, História da fundação do Império do Brasil (1864-1868), em sete volumes; Segundo período do Reinado de D. Pedro I no Brasil (1871) e História do Brasil de 1831 a

\footnotetext{
* Os textos citados ou transcritos têm a ortografia atualizada, em conformidade com o Acordo Ortográfico da Língua Portuguesa de 1990.

1 Cf. <http://www.academia.org.br/academicos/j-m-pereira-da-silva >.

2 Atual Nova Iguaçu.

3 Ainda não foi possível confirmar a cidade em que se deu o falecimento do escritor: no site da ABL consta que seu óbito ocorreu em Paris, mas há quem o localize no Rio de Janeiro.

4 Os historiadores se dividem em relação ao ano da sua formatura: 1837 ou 1838 .
}

1840 (1879). No final da vida, retratou a situação política brasileira no perído de 1840 a 1886 , em dois volumes intitulados Memórias do meu tempo. Além das suas criações literárias, destacam-se no campo literário, os dois volumes do Parnaso brasileiro (1843 e 1848), antologia acompanhada por longo ensaio sobre a nossa literatura. Renome granjeou também o Plutarco brasileiro (1847) que, reeditado sob o título de Varões ilustres do Brasil durante os tempos coloniais (1858), reúne uma série de biografias de figuras proeminentes da colônia brasileira.

O papel relevante que este infatigável polígrafo desempenhou na sociedade brasileira, a importância e a influência da sua obra ainda não foram objeto de estudos esclarecedores e aprofundados. No entanto, muitas restrições têm sido feitas à sua produção biográfica, histórica e literária, entre as quais sobreleva, pela sua virulência, o juízo negativo de José Veríssimo, ao afirmar que a

sua obra copiosa $[\ldots]$ importante pelos assuntos pouco vale pelo fundo e pela forma. Historiador escreveu história com pouco estudo, com quase nenhuma pesquisa, sem crítica [...] Sabendo-se como ele fazia história, avalia-se como faz romance histórico. Os seus realmente não têm valia alguma como quadro das épocas que presumem pintar, nem qualidades de imaginação ou expressão que lhes atenuem esse defeito (VERÍSSIMO, 1969, p. 151-152). 
A reduzida bibliografia sobre Pereira da Silva está, contudo, enfermada por afirmações infundadas, lacunas e enganos. No site da Academia Brasileira de Letras explica-se que ele não recebeu o habitual elogio do seu sucessor, pelo fato de o Barão do Rio Branco ter sido empossado por correspondência. Não sendo os ocupantes seguintes da mesma cadeira obrigados a fazê-lo, o seu perfil e a sua obra permaneceram sem exame naquele cenáculo. Mas este não é o nosso propósito pois visamos apenas demonstrar a posição destacada do escritor fluminense nas origens da ficção brasileira, apontando as informações incorretas sobre a data de publicação das suas primeiras criações e os preconceitos subjacentes à apreciação das mesmas. Informações erradas encontram-se, por exemplo, no site da Academia Brasileira de Letras, onde se pode ler que Pereira da Silva "estreou como ficcionista, em 1838, com o romance Uma paixão de artista, ao qual se seguiram as novelas históricas $O$ aniversário de D. Miguel em 1828, em 1839, e Jerônimo Corte Real, em 1840"5.

Tais indicações falham ao apontar 1838 como o ano de estreia do ficcionista e como sua produção inicial o 'romance' Uma paixão de artista. Deixando de lado a complexa questão dos subgêneros da prosa de ficção, a pesquisa comprovou que, já em 1837, Pereira da Silva deu à luz, no periódico carioca Gabinete de Leitura. Serões das famílias brasileiras. Jornal para todas as classes, sexos e idades, 6 pequenos contos ou novelas. A publicação de tais narrativas não é de somenos, pois o interesse pelas origens do romance brasileiro atravessa toda a nossa historiografia literária, sendo ao contrário pouquíssimo discutida a problemática delimitação deste subgênero, em particular no século XIX.

Como demonstrou a equipe do projeto Caminhos do romance no Brasil, coordenado por Márcia Abreu, no Oitocentos, escritores, editores e livreiros atribuíam com frequência designações diversas e contraditórias às narrativas e, por vezes, até à mesma narrativa. É o caso de Pereira da Silva, que apresenta como 'legenda brasileira' a sua "Luísa", como 'novela brasileira', "Amor, ciúme e vingança", como 'romance histórico', "Religião, amor e pátria", como 'crônica', Jerônimo Corte Real. $\mathrm{O}$ uso indiscriminado desses conceitos e a indefinição do que é romance, novela ou conto põem em xeque a(s) escolha(s) do romance inaugural da literatura brasileira pela historiografia literária ${ }^{6}$.

\footnotetext{
5 Cf.. <http://www.academia.org.br/academicos/j-m-pereira-da-silva>.

6 Há quem situe a origem do romance brasileiro no período colonial, indicando para o efeito a História do predestinado peregrino e de seu irmão Precito (1682), do Padre Alexandre de Gusmão, e as Aventuras de Diófanes (1752), de Teresa Margarida da Silva Orta. Textos que outros descartam com o argumento de que não tratam do Brasil, nem dos brasileiros, ao contrário do Compêndio narrativo do peregrino da América (1768), de Nuno Marques Pereira, que, apontado também como
}

De qualquer forma, prevalece hoje o entendimento de que o romance, ou melhor, a prosa de ficção brasileira surge com o Romantismo e de que os seus primeiros esboços se encontram nos periódicos. Assim sendo, o nome de Pereira da Silva ganha proeminência. Massaud Moisés, por exemplo, indica como 'romances' inaugurais da nossa literatura "O aniversário de D. Miguel em 1828" e "Religião, amor e pátria", ambos de 1839. Esta questão foge contudo ao âmbito deste estudo, centrado, como já foi referido, na ficção que ele editou em 1837.

\section{Pereira da Silva e o Romantismo brasileiro}

Um dos primeiros propagandistas brasileiros do Romantismo, João Manuel Pereira da Silva apontou diretrizes para a criação literária nacional nos "Estudos sobre a literatura", artigo incluído no segundo número da revista Niterói, em que deu seguimento às ideias expostas pelos europeus - especialmente Ferdinand Denis e Almeida Garrett ${ }^{7}$ - e por Gonçalves de Magalhães que, no primeiro número da mesma revista, publicara o seu renomado "Ensaio sobre a história da literatura do Brasil". Relacionando a literatura à história do povo que a produziu e realçando-lhe o valor moral, Pereira da Silva defende que ela "é sempre a expressão da civilização" e que "Quanto mais se espalha o gosto e a independência da Literatura em uma nação, tanto mais ela floresce e medra" (SILVA, 1836, p.214). Sustenta ainda que, no começo do século XIX, a poesia romântica "levantou o seu estandarte vitorioso em toda a Europa", o mesmo não acontecendo no Brasil, pois

\begin{abstract}
nossos vates renegam sua pátria, deixam de cantar as belezas das palmeiras, as deliciosas margens do Amazonas e do Prata, as virgens florestas, as supertições e pensamentos de nossos patrícios, seus usos, costumes, e religião para saudarem os Deuses do Politeismo Grego [...] e destarte não passam de meros imitadores, e repetidores de ideias e pensamentos alheios (SILVA, 1836, p. 238).
\end{abstract}

\footnotetext{
o nosso primeiro romance, é por sua vez rejeitado como obra de moral e edificação religiosa. Ao afirmar que nada do que foi produzido no período colonial pode ser chamado romance ou novela, José Veríssimo (VERÍSSIMO, 1969) alinha-se com o pensamento dominante na atualidade segundo o qual o romance brasileiro surge com o Romantismo. Mantêm-se contudo divergências na definição do romance inaugural. Heron de Alencar (ALENCAR, 1969, p. 219-226) dá a primazia a Statira e Zoroastes (1826), de Lucas José de Alvarenga, precedência contestada por Massaud Moisés que entende tratar-se de narrativa, "de caráter alegorizante entroncada no didatismo iluminista» e sem influência sobre as do terceiro decênio do século XIX, às quais teria cabido "inaugurar nossa prosa de ficção romântica» (MOISÉS, 1984, p. 57-58).

7 Datados de 1826, o Resumé de l'histoire littéraire du Brésil, de Ferdinand Denis, e o Bosquejo da história da poesia e língua portuguesa, de Almeida Garrett, estão na base da ideologia nacionalista do Romantismo brasileiro.
} 
Vendo, portanto, no Romantismo o movimento que promoveria as reformas literárias necessárias à autonomia e nacionalização da literatura brasileira, à qual atribui a patriótica missão de colaborar no desenvolvimento do país, incita os escritores a preparem-se para essa tarefa, reunindo facetas de artista, historiador, filósofo e político, o que ele próprio procurou fazer.

Pouco atentos às 6 narrativas que o autor de "Religião, amor e pátria" - título aliás muito significativo - editou em 1837, alguns críticos não o consideraram um escritor verdadeiramente brasileiro, preconceito cuja origem poderá assentar numa afirmação do próprio Pereira da Silva, certamente mal interpretada por José Veríssimo, ao assinalar que ele "Ufanava-se com motivo no prefácio da primeira edição do seu Jerônimo Corte Real, crônica do século XVI de que este era um dos primeiros da literatura portuguesa moderna" (VERÍSSIMO, 1969, p. 152).

Ainda que não se possa saber o que teria levado o nosso escritor a enunciar tal parecer, convém lembrar que, à época, discutia-se não só existência duma literatura 'brasileira', mas também a designação ajustada aos textos literários oriundos do Brasil. Renomado defensor luso da autonomia da nossa literatura, Almeida Garrett, que, em 1826, aclamou Basílio da Gama como o "mais nacional [dentre] seus compatriotas brasileiros", afirmou também que "começa[va] a literatura portuguesa a avultar e enriquecer-se com as produções dos engenhos brasileiros" (apud CÉSAR, 1978, p.91 e 90). Duas décadas mais tarde, José da Gama e Castro ainda sustentava que "a literatura não toma o nome da terra, toma o nome da língua" em que é vazada (apud CÉSAR, 1978, p. 124).

Massaud Moisés assume - contradizendo-se - que Pereira da Silva pertence à literatura portuguesa e, só por circunstâncias biográficas, está ligado à brasileira. Alega que, "fiel até o fim à formação lusíada, [ele] situa-se meio à margem de nosso processo romântico" e sustenta este juízo nos seguintes argumentos: sua "sintaxe [é] castiçamente lusitana", "sua dicção é mais dum lusitano que dum brasileiro", "suas novelas se passam na Europa, sobretudo em Portugal"; "êmulo de Garrett e Herculano, [está] engajado na narrativa histórica à luz dos seus ensinamentos"; "os temas buscou-os na história de Portugal e quando optou por assunto nacional (Manuel de Morais) certamente procedeu sabendo que remetia para o continente europeu" (MOISÉS, 1984, p. 61-62).

Se parte desses aspectos pode ter alguma validade quando aplicada às narrativas históricas do escritor, carece de comprovação a sua sintaxe lusitana, o que, ainda assim, não justificaria a exclusão da nossa literatura, pois Pereira da Silva não é o único brasileiro a redigir castiçamente, tal como não foi o único a procurar emular Garrett e Herculano. Não tendo sido apontadas marcas concretas de tal influência, é igualmente pouco objetiva a afirmação de que, tendo optado por assunto nacional, Pereira da Silva buscava público europeu.

Machado de Assis apontou, há muito, a improcedência da ideia de só pertencerem à literatura brasileira obras de assunto local e demonstrar-se-á que Pereira da Silva, homem do seu tempo e espaço, manifestou na sua ficção não só o 'instinto de nacionalidade' referido pelo criador de Brás Cubas, mas ainda criou histórias e personagens brasileiras, situando-as no tempo e no espaço nacionais.

\section{A prosa de ficção de Pereira da Silva no Gabinete de Leitura: pioneirismo, romantismo e nacionalismo}

O nacionalismo literário de feição romântica preconizado por João Manuel Pereira da Silva no artigo da revista Niterói, datado de 1836, consubstanciouse nas criações ficcionais que ele publicou, no ano seguinte, no Gabinete de Leitura. Serões das famílias brasileiras. Jornal para todas as classes, sexos e idades. Editado no Rio de Janeiro, pela Tipografia Comercial, este periódico semanal, de que saíram 35 números, nos 9 meses em que circulou (de agosto de 1837 a abril de 1838), desempenhou papel importante no processo de constituição da nossa prosa de ficção. Como revelou Maria Angélica Lau Soares, "o Gabinete de Leitura dedicou mais de três quartos de suas 280 páginas à publicação de textos ficcionais" (SOARES, 2008, p. 69), que totalizam 92 títulos, 14 dos quais de autores brasileiros. A mesma pesquisadora observa que o jornal, "leva[ndo] ficção para dentro dos lares brasileiros por um preço mais acessível" (SOARES, 2008, p. 69) pretendia habituar os leitores a esse gênero de escrita e, consequentemente despertar-lhes o gosto por leituras mais longas e refletidas.

No pequeno conjunto de autores brasileiros com textos publicados no Gabinete de Leitura sobreleva Pereira da Silva que soma 6 narrativas: "Luísa. Legenda brasileira", "Uma aventura em Veneza", "Um primeiro amor", "As catacumbas de S. Francisco de Paula", "Um último adeus" e "Maria". Classificados pelos críticos como contos breves ou embriões de novelas, esses textos ocupam entre 2 e 5 colunas, o que está em conformidade com pequena dimensão do jornal e o diminuto espaço atribuído a cada escrito. As narrativas de Pereira da Silva têm como traços principais a assimilação dos modelos do Romantismo europeu e o propósito de produzir 'literatura nacional', através da criação de histórias, personagens e cenários brasileiros.

\footnotetext{
A má qualidade do microfilme desse periódico consultado na Hemeroteca Digital Brasileira (site: memoria.bn.br/hdb/periodico.aspx) não possibilita a identificação das páginas em que estão as narrativas de Pereira da Silva o que impede a sua menção nas transcrições e nas referências bibliográficas do final deste artigo.
} 
Circunscritos em geral no espaço e no tempo, os acontecimentos narrados situam-se ora no presente ora no passado da sociedade brasileira, que retratam com algum realismo e ambicionada cor local. Todas as histórias narradas - excluída "Uma aventura em Veneza" - se passam na então Província do Rio de Janeiro: "Luísa", na vila de Iguaçu, e as demais ("Um primeiro amor", "Um último adeus", "As catacumbas de S. Francisco de Paula" e "Maria") na Corte carioca. Massaud Moisés que pretendeu encaixar Pereira da Silva na literatiura portuguesa apontou, contudo, na eleição do espaço carioca o intuito de 'abrasileirar a ficção', transplantando-a para a nossa ambiência.

Embora "Uma aventura em Veneza" se passe, como o seu título anuncia, naquela cidade italiana, o relato não foge ao propósito romântico de 'abrasileirar' a ficção, pois o seu protagonista - um brasileiro de visita a Veneza - relembra sua pátria e a compara com a afamada capital do Vêneto. Além de estranhar que uma jovem veneziana o queira levar a um baile de carnaval para o qual não fora convidado e onde não conhece pessoa alguma, o protagonista-narrador se questiona sobre " $\mathrm{O}$ que se diria no Rio de Janeiro, se uma donzela se disfarçasse com falsas vestes, e se mascarasse, e passeasse só pelas ruas" (SILVA, 1837b).

Portugal não está, porém, totalmente ausente das narrativas de Pereira da Silva, pois na intriga de "Luísa" - passada na altura em que D. João VI chega ao Brasil "fug[indo] à fúria do leão do século XIX" (SILVA, 1837a) -, conta-se que o jovem amado pela protagonista foi enviado, com o seu batalhão, para a defesa de Portugal, "que então havia esquecido a glória do século XVI, o valor dos Meneses e dos Albuquerques" (SILVA, 1837a). Entretanto, a presença portuguesa no universo recriado transparece sobretudo na herança deixada pelos colonizadores na organização social, nos hábitos e costumes, na arquitetura e, acima de tudo, na religião católica.

Nos textos em análise assumem também grande importância a pintura da paisagem brasileira $e o$ sentimento da natureza, característico do Romantismo. O propósito de nacionalização da nossa literatura explica que, em narrativas tão breves, o escritor fluminense se tenha alongado na celebração das paisagens naturais ou urbanas do Brasil. É o que acontece quer, em "Luísa", cujo narrador exalta a paisagem interiorana do Rio de Janeiro -

Aqueles que já navegaram pelo rio Iguaçu devem recordar-se de uma vasta e bela campina, situada à sua margem direita, e distante três léguas da barra. [...] O rio majestosamente atravessa a campina, despejando suas brancas águas por entre mil belezas naturais, amenas planícies, lindíssimas montanhas. $[\ldots]$

Oh! que felicidade não é o respirar essa atmosfera melancólica dos bosques esse aroma virginal das florestas (SILVA, 1837a).

- quer, em "Um último adeus", em que um sacerdote dialogando com um jovem desesperado, devido à inesperada morte da sua futura esposa, tenta reanimá-lo, chamando a sua atenção para a beleza extraordinária da entrada da Baía da Guanabara:

- Repara como a natureza se esforçou em fazer desta terra o paraíso do mundo!... Que há no globo de mais soberbo que a entrada desta capital?... Estas montanhas tão verdes dão um ar de majestade e de grandeza à minha pátria; incute o respeito no ânimo dos estrangeiros, que aqui chegam, e entretanto, se ecetuarmos a magnificência da natureza, que cousa temos por nós feita que dê ideia ao mundo civilizado de que nós existimos? (SILVA, 1837e).

Brasileiras são quase todas as personagens dos relatos em análise, sendo a sua naturalidade frequentemente mencionada e sobrevalorizada. Em "Um primeiro amor", diz-se que "Carolina eclipsava com sua beleza a formosura das outras donzelas" e que "Seus olhos traiam a sua origem brasileira" (SILVA, 1837c). Em "As catacumbas de S. Francisco de Paula", Eustáquio quando via na Europa uma jovem bonita "comparava[-a] imediatamente com Amélia, e a brasileira ganhava no paralelo" (SILVA, 1837d). Em "Luísa", o narrador, descrevendo a protagonista, afirma ser "o seu todo um modelo perfeito de graças, que não temia apresentar-se ao lado das Vênus de Canova e de Médicis" (SILVA, 1837a). Tal como o narrador-personagem de "Uma aventura em Veneza", é brasileiro o de "As catacumbas de S. Francisco de Paula" que, regressado da Europa, vai ao local que dá título ao relato para rezar junto ao túmulo de seus pais.

Por outro lado, os traços físicos, o perfil psicológico e as ações das personagens de Pereira da Silva - sucinta mas cuidadosamente compostas pelo autor - configuram tipos humanos característicos da literatura romântica, mas não monoliticamente voltados para o bem ou para o mal. É o caso de Maria - protagonista do relato homônimo que, por considerar sua honra conspurcada por Camilo que tentara violentá-la, manda assassiná-lo e suicida-se, após confessar o seu crime. (SILVA, 1837f). É também o de Eustáquio - personagem central de "As catacumbas de S. Francisco de Paula" - que, impedido de unir-se com a sua amada

"havia já sorvido até a última gota na taça das delícias e prazeres mundanos" e cuja "alma parecia decrépita e estragada $[. .$.$] toda absorvida em um desesperado$ ceticismo" (SILVA, 1837d). 
Sem aplacar a sua revolta, Eustáquio manifesta tamanho desinteresse pela jovem inocente e virtuosa com quem se casa que lhe causa mortal sofrimento. "Ele seguiu o seu corpo às catacumbas, e chorou um dia inteiro" (SILVA, 1837d).

Romântico é, sem dúvida, o motor que rege a ação de numerosas personagonistas, visto que a paixão é o fulcro das suas vidas, nas quais preponderam o amor impossível e seus correlatos - sofrimento, ciúme, pecado, traição, crime, vingança -, assim como o final trágico: a morte ou a reclusão no convento.

Dentre as diversas personagens que, nas narrativas em análise, são membros da Igreja Católica, destaca-se Henrique, o sacerdote de "Um último adeus", já aqui referido. Como em muitas outras histórias românticas de relações amorosas frustradas, esta personagem se fez padre por ter sido impedida de casar-se com a sua amada Eugênia, devido à inferioridade de sua condição social. Por destino similar optou Eugênia que, tendo ingressado num convento, morre trazendo ainda no dedo o anel que Henrique lhe havia oferecido. O jovem a quem o sacerdote conta a sua história e que também sofre a perda da mulher amada decide igualmente entrar para um convento.

Tem igualmente forte presença nas histórias de Pereira da Silva o sentimento religioso das personagens leigas e do narrador, de que são exemplos a já referida visita do narrador-personagem às catacumbas de São Francisco de Paula, no conto de igual título, e o desejo de confessar-se revelado por Maria, protagonista da narrativa que tem o seu nome. Deste último, leia-se o seguinte fragmento:

Apenas chegou aos ouvidos de Maria a notícia de tal morte, ela mandou chamar um sacerdote, e, cumprindo com os deveres que lhe impunha a religião Católica Apostólica Romana, lhe confessou que se havia vingado de Camilo, que the havia imprimido uma nódoa eterna; depois que a abençoou o santo sacerdote, ela lançou mão de uma porção de veneno que já tinha preparado e misturando-o com água, o sorveu todo... (SILVA, 1837f).

No que respeita aos sentimentos religiosos, esta cena não deixa, contudo, de provocar alguma estranheza, pois Maria peca duas vezes contra a religião que professa: manda matar Camilo e suicida-se. Paradoxos de que não estão isentos as criaturas e nos quais atenta o seu criador.

Marca essencial da ficção romântica, o autor ocupa lugar proeminente no texto, valendo-se ora do relato em $1^{a}$ pessoa, ora da narração externa e omnisciente. Neste caso, o narrador-autor implícito interfere frequentemente no narrado, seja para assegurar a veracidade do que conta - de que é exemplo uma passagem de "Luísa":
Nós visitamos com respeito esse lugar, e ainda hoje a reminiscência nos acompanha como um belo sonho; é por isso que nos arriscamos a publicar a história da bela Luísa (SILVA, 1837a).

- seja para manifestar os seus pontos de vista e sentimentos, como ocorre no seguinte fragmento de "Um primeiro amor":

Um primeiro amor jamais se apaga da lembrança, a primeira sensação, que sofremos, com dificuldade se risca da memória. É a vida inteira que consagramos quando sentimos palpitar o coração com tal paixão; é a existência neste mundo e a eternidade no outro, que então perdemos... (SILVA, 1837c).

Ainda maior destaque assumem a personalidade e visão de mundo do autor na composição de narradorespersonagens, que nada mais são do que máscaras de que ele se vale para participar no narrado. Em «As catacumbas de S. Francisco de Paula», o narrador que, como já se disse, acabara de regressar da Europa, relata a história duma jovem senhora enterrada no cemitério onde repousam os seus pais. Ao apresentar a trágica história que lhe foi contada por um velho negro, aproveita para descrever o seu próprio sofrimento, bem como as "ideias religiosas e fúnebres", que o atormentavam:

a cada passo eu estremecia [...] eu ia beijar os restos daqueles que me haviam dado ao mundo, e para quê? [...] Depois de haver cumprido com os deveres de um filho agradecido, depois de haver derramado algumas lágrimas sobre a solitária urna, esforcei-me em dar tréguas à minha dor, passeando por entre aqueles túmulos, e, à vista de tantos mortos, infundir n'alma algumas gotas de consolação (SILVA, 1837d).

Em "Uma aventura em Veneza", outro narradorpersonagem narra o que lhe aconteceu ao ver uma senhora que ia aos bailes para chorar a perda de filho que muito amara. Tendo derramado também uma lágrima, a personagem-narradora - um "solitário brasileiro" que se "julgava o mais infeliz dos homens" - divaga longamente sobre o presente e o passado de Veneza, sobre a diferença de costumes na Itália e no Brasil e, em especial, sobre a sua infelicidade e a da sua distante pátria, carente de liberdade e de progresso:

Entretanto, enquanto Veneza se engolfava nos prazeres, ao som de diversos instrumentos que tocavam curiosos, eu estava tristemente sentado no pedestal da coluna de porfiro, que sustenta o brônzeo leão de S. Marcos [...], a minha imaginação melancólica me rasgava o painel do passado [...], entretanto um sorriso parecia sair dos restos de tão grandes palácios que ornam as ribas do Rialto; e era eu quem me entristecia, eu na primavera 
dos anos, na manhã da vida, no tempo das ilusões, das crenças e da volubilidade!... Sim porque eu reconhecia então a analogia com a da minha pátria; eu estava a duas mil léguas distante dela, e a via iludida, a via desconhecendo o caminho da verdadeira liberdade, do progresso e da civilização (SILVA, 1837b).

É por sua vez tipicamente romântico o estilo de Pereira da Silva, impregnado de subjetividade, de sentimentalismo, de imagens e de colorido, como se lê nos fragmentos já transcritos e no que se segue:

Às margens do rio Iguaçu há um lugar ermo e solitário, respeitado por todos os habitantes daquele país. É um bosque formado de árvores, que se assemelham aos ciprestes europeus, elevando seus ramos aos céus, como se fossem as súplicas dos homens; e estes ramos, e as folhas que os ornam, jamais murcham, ainda que tenham um aspecto melancólico e misterioso, ainda que pareçam ser caracterizados por uma dor profunda, como um primeiro amor que não é correspondido (SILVA, 1837a).

Como evidenciam as seguintes passagens, marcam também presença nos seus escritos a ironia típica do Romantismo:

Consta que Eugênio, [...], voltando de Paris, formado em medicina, teve um grande pesar da morte daquela a quem pretendia unir-se, mas que, como jovem e doutor, breve se consolara, e desposara uma bela viúva de 45 anos, que tinha muito dinheiro (SILVA, 1837f).

E digam depois esses espíritos mesquinhos e ignorantes que em S. Paulo nada se aprende!... Os bailes têm constantemente provado o contrário (SILVA, 1837c).

São também bastante frequentes nos textos do autor as alusões críticas à política brasileira e aos que a conduziam:

corria, por certo, que o tal deputado, que ainda se ignora como pudesse ser nomeado por uma província tão ilustrada, $[. .$.$] era dos que, quando iam à Câmara,$ se sentavam no banco e não se levantavam senão para a votação, fazendo voto de castidade de língua, exceto nos momentos dos monossílabos que necessitavam o - apoiado - para dar a ideia a seus constituintes de que ele não se esquecia dos seus interesses (SILVA, $1837 \mathrm{c})$.

\section{Conclusão}

Se, de fato, no Brasil, a produção ficcional em prosa é contemporânea da introdução do Romantismo e foi inicialmente divulgada através de jornais e revistas, sendo, por sua vez, muito raros os textos de escritores brasileiros editados antes de 1837, cumpre concluir que as 6 narrativas publicadas neste ano por João Manuel Pereira da Silva, no Gabinete de Leitura exigem que ele seja considerado um dos criadores da narrativa de ficção brasileira. Os seus "contos" - redigidos quando ele ainda residia em Paris ou pouco depois da sua chegada ao Rio de Janeiro - constituem o seu primeiro contributo para criação duma literatura brasileira autônoma e a serviço dos ideais nacionalistas, pelos quais o escritor fluminense propugnara no artigo lançado na revista Niterói, um ano antes.

A par com o pioneirismo, deve-se reconhecer que o autor do Plutarco brasileiro assinalou inúmeros caminhos pelos quais enveredaram os seus contemporâneos e mais próximos sucessores. Os folhetins editados pelos seus pares em diversos periódicos brasileiros revelam características semelhantes às das suas narrativas do Gabinete de Leitura, visto que, sendo todos caudatários das diversas modalidades da ficção romântica europeia, empenharam-se, tal como o criador de «Luísa», na busca do abrasileiramento da nossa ficção.

Ainda que as reduzidas dimensões dos textos do Gabinete de Leitura e de outros que Pereira da Silva publicou pouco depois noutros periódicos tenham levado alguns historiadores a the recusarem o papel de fundador do romance brasileiro ${ }^{9}$ - problema aliás insolúvel - é incontestável que ele pertence à literatura brasileira e que ocupa importante lugar na formação da nossa narrativa de ficção.

Convém, pois, que os apreciadores e os estudiosos da literatura brasileira leiam e analisem o conjunto da produção ficcional do fundador da cadeira $34 \mathrm{da}$ Academia Brasileira de Letras que tão carente está de uma profunda revisão crítica.

\section{Referências}

ALENCAR, Heron de. Precursores. O primeiro romance. In: COUTINHO, Afrânio (Dir.). A literatura no Brasil. 2. ed. Rio de Janeiro: Editorial Sul Americana: 1969. v. 2. p.219-226.

CANDIDO, Antonio. Formação da literatura brasileira. Momentos decisivos. 2. ed. rev. São Paulo: Livraria Martins Editora, 1964. v. 2.

CASTRO, José da Gama. Correspondência. In: CÉSAR, Guilhermino. Historiadores e críticos do Romantismo. 1. A contribuição europeia: crítica e história literária. Rio de Janeiro/São Paulo: Livros Técnicos e Científicos/EdUSP, 1978. p. 123-126.

DENIS, Ferdinand. Résumé de l'histoire littéraire du Portugal suivi du Résumé de l'histoire littéraire du Brésil. Paris: Lecointe et Durey Lib., 1826.

\footnotetext{
Para José Veríssimo, "romance propriamente dito, o primeiro é o Filho do pescador" (VERÍSSIMO, 1969, p. 150), publicado em 1843 por Teixeira e Sousa, opinião partilhada por Antonio Candido, para quem os textos que o antecederam, "apesar de trazerem por vezes esta designação, têm dimensões de conto ou novela» (CANDIDO, 1964, p. 121).
} 
GARRETT, Almeida. Bosquejo da história da poesia e língua portuguesa. In: CÉSAR, Guilhermino. Historiadores e críticos do Romantismo. 1. A contribuição europeia: crítica e história literária. Rio de Janeiro/São Paulo: Livros Técnicos e Científicos/EdUSP, 1978. p. 87-92.

MAGALHÃES, Domingos José Gonçalves de. Ensaio sobre a história da literatura do Brasil. Niterói, Revista Brasiliense de Ciências, Letras e Artes, Paris: Dauvin et Fontaine Libraires, t. I, n. 1, p. 132-159, 1836.

MOISÉS, Massaud. Primeiro momento romântico 2. Prosa. In: História da literatura brasileira: romantismo, realismo. 2. ed. São Paulo: Cultrix/EdUSP, 1984. p. 56-101.

SILVA, João Manuel Pereira da. Estudos sobre a literatura. Niterói, Revista Brasiliense de Ciências, Letras e Artes, Paris: Dauvin et Fontaine, Libraires, t. I, n. 2, p. 214-242, 1836.

SILVA, João Manuel Pereira da. Luiza. Legenda brasileira. Gabinete de Leitura. Serões das famílias brasileiras. Jornal para todas as classes, sexos e idades, Rio de Janeiro, n. 10, 1837a.

SILVA, João Manuel Pereira da. Uma aventura em Veneza. Gabinete de Leitura. Serões das famílias brasileiras. Jornal para todas as classes, sexos e idades, n. 11. Rio de Janeiro, 1837b.

SILVA, João Manuel Pereira da. Um primeiro amor. Gabinete de Leitura. Serões das famílias brasileiras. Jornal para todas as classes, sexos e idades, n. 13. Rio de Janeiro, 1837c.

SILVA, Pereira da. As catacumbas de S. Francisco de Paula. Gabinete de Leitura. Serões das famílias brasileiras. Jornal para todas as classes, sexos e idades, n. 14. Rio de Janeiro, 1837d.
SILVA, João Manuel Pereira da. Um último adeus. Gabinete de Leitura. Serões das famílias brasileiras. Jornal para todas as classes, sexos e idades, n. 15. Rio de Janeiro, 1837e.

SILVA, João Manuel Pereira da. Maria. Gabinete de Leitura. Serões das famílias brasileiras. Jornal para todas as classes, sexos e idades, n. 18. Rio de Janeiro, $1837 \mathrm{f}$.

SILVA, João Manuel Pereira da. Religião, amor e pátria. Romance histórico. Jornal do Commercio, Rio de Janeiro, 12-16/III/1839.

SILVA, João Manuel Pereira da. Jerônimo Corte-Real. Crônica portuguesa do século XVI. Rio de Janeiro: Tip. Imp. e Const. de J. Villeneuve e Comp., 1840.

SOARES, Maria Angélica Lau P. A prosa de ficção britânica no Gabinete de Leitura (1837-1808). In: ABREU, Márcia (Org.). Trajetórias do romance. Circulação, leitura e escrita nos séculos XVIII e XIX. Campinas: Mercado de Letras, 2008. p. 67-88.

VERÍSSIMO, José. Pereira da Silva. In: História da literatura brasileira. 5. ed. Rio de Janeiro: José Olympio, 1969. p. 151-153.

Recebido: 25/11/2018

Aprovado: 12/12/2018

Autora:

VANIA PINHEIRO CHAVES

Faculdade de Letras da Universidade de Lisboa (FLUL).

vaniachaves@netcabo.pt

(D) 0000-0001-8553-7170 